PERSPECTIVE

\title{
Topical ciclosporin in the treatment of ocular surface disorders
}

S Tatlipinar, E K Akpek

Br J Ophthalmol 2005;89:1363-1367. doi: 10.1136/bjo.2005.070888

Mounting evidence suggests that inflammation is the key factor in the pathogenesis of various ocular surface diseases, with a complex interplay of genetic, environmental, and psychosocial factors. Management of these conditions is often challenging. Topical corticosteroids, with their associated side effects, are the mainstay of current treatments for patients with vision threatening disease. Ciclosporin $A$ is an immunomodulator that specifically inhibits $T$ lymphocyte proliferation. Recently, a topical ciclosporin preparation was approved by the US Food and Drug Administration and became available for use in ophthalmology. Given the increasing use of ciclosporin eye drops, the goal of this article is to provide the reader with an overview of the well established uses of ciclosporin and to help refine the questions that should be addressed by future investigations.

See end of article for authors' affiliations

\section{Correspondence to:} Esen Karamursel Akpek, MD, Ocular Surface and Dry Eye Clinic, The Wilmer Eye Institute, 600 North Wolfe Street, Maumenee Building 317, Baltimore, MD 21287-9238, USA; esakpek@jhmi.edu

Accepted for publication 15 June 2005
$\mathrm{T}$ he ocular surface encompasses the entire epithelial surface of the cornea, limbus, and conjunctiva. The primary purpose of this functional unit is to maintain corneal clarity, a critical component of the eye's optical system. Even a small change in corneal clarity, such as a less than adequate tear film, can lead to visual disturbances.

Ocular surface diseases are a large group of disorders with a variety of aetiologies, symptoms, and clinical findings. These disorders range from simple meibomian gland dysfunction, with excellent prognosis, to Stevens-Johnson syndrome, which can cause permanent scarring of the conjunctiva, loss of corneal transparency and hence loss of vision, with considerable impairment in quality of life. Ironically, most patients with ocular surface disease have a healthy posterior segment with otherwise favourable visual prognosis.

Whatever the initial aetiological factor of ocular surface disease, once the disease has developed, inflammation becomes the key mechanism of injury to the ocular surface. ${ }^{12}$ There is a diversity of initiating insults, such as tear film insufficiency, chemical injury, or hypersensitivity mechanisms. When present, inflammation is augmented by mediators released from damaged cells and invading leucocytes. Hence, eyes with ocular surface disease may be trapped in a vicious cycle of inflammation and resultant injury.

Currently, the anti-inflammatory treatment of ocular surface disorders mainly relies on topical or systemic corticosteroids, which carry the risk of serious side effects. A topical ciclosporin A (CsA) preparation has recently become commercially available. CsA is an established immunomodulating drug that was originally used to prevent rejection after organ or tissue transplantation. Systemic CsA has also been employed as a treatment for a variety of autoimmune diseases, including those with ocular involvement. ${ }^{3-5}$

CsA is a neutral, hydrophobic, cyclic undecapeptide metabolite of the fungus Tolypocladium inflatum. Its major clinical effect is the perturbation of expression of interleukin-2 (IL-2) by helper $\mathrm{T}$ cells, preventing the proliferation of $\mathrm{T}$ cells. ${ }^{3}$ CsA was discovered in the early 1970s as an antifungal agent. Later, owing to its lack of bone marrow toxicity, ${ }^{6}$ it assumed a leading role in solid organ transplant surgery, ${ }^{7}$ with dramatically improved patient prognosis. In ophthalmology, topically applied CsA in various oil based solvents was first used to inhibit experimental corneal allograft reaction in the early $1980 \mathrm{~s}^{8}$; this was followed by human studies. ${ }^{10}$ Later, the drug proved useful for patients with various inflammatory ocular surface disorders. ${ }^{11} 12$

The main problems with the eye drop preparation of CsA were sterility, $\mathrm{pH}$, particles, and its lipophilic properties. A licensed topical CsA $(0.2 \%$ in ointment form, Optimmune, Schering-Plough) has been available in veterinary ophthalmology for the treatment of canine keratoconjunctivitis sicca, but the introduction of a similar preparation for human pharmacy $(0.05 \%$ eye drop form, Restasis, Allergan Inc) did not occur until April 2003. This preparation has now been approved by the Food and Drug Administration for use in the treatment of dry eye condition in humans. Given the increasing use of this product in patients by practising ophthalmologists for various indications, the goal of this analysis was to evaluate the peer reviewed published scientific literature, to define well established uses of CsA eye drops, and to help refine the important questions to be addressed by future investigations.

\section{DRY EYE SYNDROME}

Dry eye syndrome is a common disorder of the tear film that results in epithelial damage and the disruption of normal homeostasis at the ocular surface. Clinical features of dry eye syndrome include an unstable tear film, ocular surface inflammation, and epitheliopathy, resulting in symptoms ranging from discomfort to blindness. ${ }^{13}$

Abbreviations: CsA, ciclosporin A; IL-2, interleukin-2; PUK, peripheral ulcerative keratitis 
Dry eye syndrome is widespread with as many as $25 \%$ of patients visiting ophthalmologists reporting dry eye symptoms. ${ }^{14}$ The current understanding of the pathogenesis of dry eye disease has proceeded from the mere recognition of a lack of, or altered quality of, tears to recognition of inflammation as the key pathogenetic mechanism, whether from a systemic autoimmune disease or a local autoimmune event. ${ }^{15}$ Inadequate tear production and low tear clearance, for whatever reason, lead to chronic inflammation of the ocular surface, mediated mainly by $\mathrm{T}$ lymphocytes. ${ }^{15}$ Moreover, the conjunctival T cell subpopulations do not differ significantly in Sjögren's syndrome and non-Sjögren's syndrome patients with dry eye. ${ }^{16}$ Androgens also represent an important trophic factor for the ocular surface, and their deficiency predisposes to inflammation from both lacrimal and meibomian gland dysfunction. ${ }^{17}$ Immune based inflammation can therefore interconnect and negatively reinforce these different pathogenetic mechanisms, resulting in a vicious cycle and subsequent ocular surface damage.

The traditional approach to treating dry eye has been to lubricate the ocular surface by replacing or conserving the patient's tears, without correcting the underlying disease process. Yet these treatments do not directly address the ocular surface inflammation.

Anti-inflammatory therapies are considered for patients with moderate to severe dry eye syndrome who continue to have symptoms or who have evidence of corneal disease on aqueous enhancement therapies. Several clinical studies have shown topical corticosteroids to improve both signs and symptoms of dry eye. ${ }^{18} 19$

In preliminary studies on small groups of patients, treatment with topical CsA improved the signs and symptoms of dry eye syndrome. ${ }^{20-22}$ Evidence of the inflammatory nature of dry eye syndrome and the success of the preliminary investigations led to large scale multicentre, randomised, placebo controlled, double masked, dose ranging clinical trials of the efficacy and safety of topical CsA therapy in moderate to severe dry eye syndrome. A CsA oil in water emulsion formulation significantly improved the ocular signs and symptoms of moderate to severe dry eye in patients with or without Sjögren's syndrome, and was found to be safe and well tolerated..$^{23}$ In this phase 2 study, of the four different CsA dosing regimens $(0.05 \%, 0.1 \%, 0.2 \%$, and $0.4 \%$ ), the $0.05 \%$ dose gave the most consistent improvement in symptoms. Following this study, the efficacy and safety of topical $0.05 \%$ and $0.1 \%$ CsA were compared with vehicle in patients with moderate to severe dry eye syndrome. ${ }^{24}$ As in the phase 2 study, both formulations were reported to be safe and effective, and the $0.05 \%$ formulation produced significantly greater improvements in signs (that is, corneal staining and Schirmer values) and symptoms (blurred vision, need for concomitant artificial tears, and the physician's evaluation of global response to treatment). The 877 patients ( 293 in the $0.05 \%$ CsA group, 292 in the $0.1 \%$ group, and 292 in the vehicle group) in the study were treated for 6 months. In addition, a subset of patients from the phase 3 study underwent conjunctival biopsy before and after treatment with topical CsA, in order to investigate the effect of treatment on ocular surface histopathology. An increase in goblet cell counts was reported in association with clinical improvement. ${ }^{25}$ Reduced numbers of activated lymphocytes in conjunctiva ${ }^{26}$ and a decrease in IL-6 in conjunctival epithelium ${ }^{27}$ were also observed.

Evidence obtained from these studies supports the efficacy of topical CsA treatment through its immunomodulatory action and a possible direct lacrimogenic effect as shown in a canine model in reversing inflammation of the ocular surface and lacrimal glands and in improving the signs and symptoms of dry eye syndrome in patients with or without
Sjögren's syndrome. However, the optimal dosing and required duration of treatment are not known.

\section{VERNAL KERATOCONJUNCTIVITIS}

Vernal keratoconjunctivitis is a severe, chronic allergic disorder, seen primarily in young males, often with a history of atopy. The hallmark sign of vernal keratoconjunctivitis is giant papillae on the upper tarsal conjunctiva, although in some patients limbal oedema may be predominant.

The disease tends to be self limited and frequently disappears after the teen age period, but a chronic, more severe form of disease can be seen in adults. In certain countries it is the most common form of conjunctivitis. ${ }^{28}$

The management of vernal keratoconjunctivitis is determined by the severity of involvement. Mast cell stabilisers are generally considered effective, based on studies from Europe and North America. ${ }^{29-31}$ However, results from the Middle East and Africa have not consistently shown benefit. ${ }^{32-34}$ Vision threatening corneal complications include central epithelial keratitis and shield-like ulcers. Topical steroids usually alleviate the acute symptoms, ${ }^{32}$ but unsupervised treatment leads to glaucoma and cataract formation in a significant proportion of patients. ${ }^{35}$ Particularly in the developing countries, vernal keratoconjunctivitis is considered a potentially blinding disease. ${ }^{36}{ }^{37}$ The search for new, effective, safe treatments of this potentially blinding disease continues. Recently, a 2 week trial of topical $0.01 \%$ mitomycin C, four times daily, proved safe and effective in the treatment of patients with severe, blinding vernal keratoconjunctivitis resistant to topical steroids. ${ }^{38}$

The immunopathogenetic mechanism is complex and involves an IgE mediated immediate hypersensitivity response as well as a Th2 type of immune reaction..$^{39}$

Multiple studies on the efficacy of topical CsA for treating vernal keratoconjunctivitis have consistently shown a beneficial effect of the drug. ${ }^{41-46}$ The improvement produced by topical CsA usually took an average of 2 weeks using $1 \%$ or $2 \%$ CsA in oil solvents, four times daily. The duration of treatment depends on the activity of the inflammation. No major adverse effect was reported, except for mild burning and stinging. A rebound phenomenon occurred soon after discontinuation of the treatment, indicating the need for a slow taper. ${ }^{41}$

\section{ATOPIC KERATOCONJUNCTIVITIS}

Atopic keratoconjunctivitis is a bilateral, inflammatory external ocular disease that manifests in the context of atopic dermatitis. There appears to be an increasing incidence of atopic dermatitis worldwide in recent years, ${ }^{47}$ possibly because of increased exposure to airborne allergens or irritants. About $25 \%$ to $40 \%$ of patients with atopic dermatitis have ocular involvement. ${ }^{48}$

Atopic keratoconjunctivitis is the most important of the allergic ocular surface disorders, because of its chronic course and frequent corneal complications that can lead to permanent loss of vision. ${ }^{49-51}$ Unlike vernal keratoconjunctivitis, atopic keratoconjunctivitis can involve both upper and lower palpebral conjunctivae, with resultant scarring indistinguishable from other causes of cicatrising conjunctivitis.

The pathogenesis of atopic keratoconjunctivitis is not fully understood, but investigators have proposed a complex immunomodulatory dysfunction at the ocular surface, including type I and type IV hypersensitivity reactions ${ }^{52}{ }^{53}$ with a predominantly Thl cytokine profile, perhaps because of the chronicity of the disorder. ${ }^{54}$

Currently available therapies are aimed, at best, at relieving symptoms; there is no evidence for a significant effect on the disease course. Corticosteroids are the mainstay of treatment, with dramatic improvement in acute symptoms. However, 
the efficacy of steroids in preventing the crippling consequences of atopic keratoconjunctivitis is not known. Corneal complications are seen in up to $60 \%$ to $70 \%$ of patients. ${ }^{49} 55$ Despite a combination treatment with topical mast cell stabilisers + oral antihistamines + intermittent topical corticosteroid, about $30 \%$ of patients require corneal transplantation for visual or tectonic purposes. ${ }^{49}$ Also, resistance to topical steroids may necessitate systemic CsA therapy. ${ }^{56}$

In two prospective, randomised, double masked, placebo controlled trials, topical CsA was found to be an effective and safe treatment in both steroid dependent and steroid resistant cases of atopic keratoconjunctivitis. ${ }^{57}{ }^{58}$ In the earlier study, ${ }^{57} 21$ patients used either topical $2 \%$ CsA or the vehicle alone four times daily for 3 months, in addition to their usual therapy with topical corticosteroids and/or mast cell stabilisers. The great majority of the treated patients were able to discontinue their topical steroid treatment. The later study ${ }^{58}$ included 20 patients with topical steroid resistant, severe atopic keratoconjunctivitis; they had moderately active disease despite topical steroid therapy with or without mast cell stabilisers. Treatment (CsA or placebo) lasted for 28 days with a dosing schedule of six times daily during the first 2 weeks and four times daily during the last 2 weeks. Significant improvement was observed in the CsA group, and none of these patients had a worsening of the disorder, in contrast with the placebo group.

Another study involving both atopic keratoconjunctivitis and vernal keratoconjunctivitis patients who had experienced no improvement with conventional therapy documented the beneficial effect of topical CsA as an additive treatment, with a reduced need for topical steroid use. ${ }^{59}$

Laboratory studies of the immunomodulatory effects of topical CsA in atopic keratoconjunctivitis have shown decreased numbers of leucocytes and CD4+ and IL-2 receptor positive $\mathrm{T}$ cells in conjunctival biopsy specimens of subjects with atopic keratoconjunctivitis following therapy ${ }^{60}$

Topical CsA seems to be an effective steroid sparing agent in patients with severe atopic keratoconjunctivitis. However, its efficacy as a first line agent during long term treatment warrants additional studies.

\section{NON-INFECTIOUS KERATITIS}

Immune mediated, sterile central or paracentral corneal ulceration may develop in patients with connective tissue disease, most commonly in rheumatoid arthritis or Sjögren's disease. These conditions need to be distinguished from peripheral ulcerative keratitis (PUK), because PUK is essentially a vasculitis of limbal blood vessels and is considered to be associated with (re)activation of systemic illness. ${ }^{61}$ Central ulcerations or keratolysis, by contrast, are not associated with a limbal vasculitis. ${ }^{62}$ Immunohistochemical studies demonstrated infiltration with macrophages, T lymphocytes, and aberrant expression of HLA class II antigens, suggesting a cellular immune reaction targeted at the cornea. ${ }^{63} 64$

The treatment should be aimed at stopping melting and encouraging re-epithelialisation. In severe cases, with corneal melting and perforation, tissue adhesives may be used. Controlling the underlying illness is essential. However, unlike PUK, the central/paracentral ulcerations may not respond well to systemic immunosuppressive therapy. ${ }^{64} 65$

Several small, uncontrolled case series have reported the beneficial effect of topical CsA in treating paracentral corneal ulcers associated with connective tissue disease. In one study, topical 2\% CsA, four times daily, was instituted in five patients with unilateral paracentral rheumatoid corneal ulceration who had not responded to systemic immunosuppression. ${ }^{64}$ Treatment resulted in an immediate arrest of keratolysis and re-epithelialisation. In another study, systemic immunosuppressive therapy either could not be initiated owing to a systemic contraindication or was discontinued because of side effects in five patients with collagen vascular diseases. ${ }^{65}$ The patients were treated with topical $2 \%$ or $0.5 \%$ CsA, four to six times daily. All but one of the eyes responded favourably with an intense neovascularisation within 48 hours of initiating treatment. In other small series sterile marginal corneal ulcers in the context of rheumatoid arthritis responded to use of $2 \%$ CsA eye drops twice daily with healing of the ulcers within several days..$^{636}$

Observation of macrophages, $\mathrm{T}$ lymphocytes, and aberrant expression of HLA class II antigens in the corneal and conjunctival tissues of patients with immune corneal ulcers associated with collagen vascular disorders suggests a cellular immune reaction. However, the current clinical evidence supporting the role of topical CsA in the treatment is weak.

\section{THYGESON'S SUPERFICIAL PUNCTATE KERATITIS}

Thygeson's superficial punctate keratitis is a bilateral, idiopathic epithelial keratitis characterised by recurrent attacks of tearing, photophobia, blurred vision, and foreign body sensation. ${ }^{67}$ The classic finding is multiple corneal epithelial lesions that appear during the exacerbations of the disease. ${ }^{68}$ Although clinical features are similar to those of viral infections, responsiveness to corticosteroids suggests an immune process, perhaps a post-infectious delayed hypersensitivity. ${ }^{69}$ However, no infectious aetiology has yet been found. ${ }^{70}$

Mild cases are often treated with lubricants and bandage lenses. ${ }^{71}{ }^{72}$ More symptomatic cases are generally treated with weak topical steroids. ${ }^{68}$ Recurrences are common following the cessation of therapy. Some patients may require regular steroid use for years. ${ }^{68}$

Reports have indicated that most patients with Thygeson's superficial punctate keratitis respond to topical CsA. ${ }^{73-75}$ In more than two thirds of the patients, topical CsA suppressed the epithelial and subepithelial opacities as long as the drug was administered. Recurrences occurred during the tapering off period. In one third of patients this therapy seemed to be curative. The results are encouraging and suggest that topical CsA may be a safe alternative to corticosteroids for the treatment of Thygeson's superficial punctate keratitis, particularly for patients who will require long term topical steroid treatment.

\section{LIGNEOUS CONJUNCTIVITIS}

Ligneous conjunctivitis is a rare form of chronic conjunctivitis characterised by the development of firm, fibrin rich, woodylike pseudomembranous lesions mainly on the tarsal conjunctiva. ${ }^{76}$ Cornea may be involved secondarily, with scarring and vascularisation.

The disorder is generally bilateral, and the onset is frequently during childhood. ${ }^{77}$ The pseudomembranes are characterised by subepithelial deposition of amorphous hyaline material; a cellular component composed of lymphocytes, plasma cells, neutrophils, eosinophils, and mast cells; and neovascularisation. The amorphous material has been shown to contain fibrin(ogen), immunoglobulins, and albumin, suggesting an increased permeability of blood vessels. ${ }^{77}$ Histopathological findings from affected humans and (plasminogen deficient) mice indicate that wound healing, mainly in injured mucosal tissues, is impaired because of markedly decreased (plasmin mediated) extracellular fibrinolysis. ${ }^{78}$ Rare immunohistochemical studies have revealed a predominance of T cells, ${ }^{79}{ }^{80}$ particularly with IL-2 receptor expression. The management of ligneous conjunctivitis is difficult, and no satisfactory treatment exists. 
Several small, uncontrolled case series of CsA therapy have indicated improvement in patients with ligneous conjunctivitis that is refractory to other modes of treatment. ${ }^{7981}$ However, contradictory reports also exist. ${ }^{80}$

\section{LICHEN PLANUS}

Lichen planus is an inflammatory dermatosis of unknown aetiology that affects the skin and mucous membranes. Classic lesions appear as recurrent, violaceous, pruritic papules distributed symmetrically on the flexor surfaces of the extremities and trunk. These lesions are often accompanied by lesions of the oral, genital, and, rarely, ocular mucosa.$^{82}$ Conjunctival lichen planus, albeit rare, can lead to irreversible damage to the ocular surface and loss of vision from corneal scarring. ${ }^{83} 84$

Although the pathogenesis is not fully understood, current findings suggest an autoimmune process mediated by $\mathrm{T}$ cells infiltrating the basement membrane and the basal layers of epithelium.

Most patients with skin involvement can be treated successfully with topical corticosteroids. Chronic, aggressive lesions may need additional therapy ranging from psoralen plus ultraviolet $\mathrm{A}$ to retinoids or CsA. ${ }^{85}$ Low dose systemic CsA may be required for patients with severe disease unresponsive to systemic steroids. ${ }^{86}$

Reported treatments of conjunctival lichen planus include CsA, mycophenolate mofetil, and azathioprine used systemically. ${ }^{83}{ }^{87}$ Because of its ability to accelerate apoptosis in fibrotic tissues, ${ }^{88}$ topical CsA alone was used in a few patients having conjunctival involvement from lichen planus, and proved effective in controlling inflammation and scarring. ${ }^{84} 89$ In particular, patients with isolated lichen planus of the conjunctiva may be candidates for topical CsA treatment with or without topical corticosteroids. ${ }^{90}$

\section{SUPERIOR LIMBIC KERATOCONJUNCTIVITIS}

Superior limbic keratoconjunctivitis is a chronic, local ocular surface disease characterised by episodes of recurrent inflammation of the upper palpebral and superior bulbar conjunctivae, as well as of the superior limbus and cornea. ${ }^{91}$ The classic finding of this condition is bilateral local hyperaemia of the superior bulbar conjunctiva. Patients often complain of burning, foreign body sensation, and photophobia. The exact pathophysiology is unknown. A mechanical theory proposed soft tissue microtrauma between tarsal and bulbar surfaces and between conjunctival stroma and sclera. ${ }^{92}$

Topical CsA was reported to be helpful as a primary or adjunctive therapy for superior limbic keratoconjunctivitis in a single study involving five patients. ${ }^{93}$ In patients with concomitant dry eye and superior limbic keratoconjunctivitis, topical CsA may be used for both increasing tear production and controlling inflammation.

\section{LESS COMMON USES OF TOPICAL CICLOSPORIN A}

There are also several, unconfirmed small case series or case reports on the use of topical CsA in the treatment of Mooren's ulcer, ${ }^{94}$ Cogan syndrome, ${ }^{95}$ chronic sarcoidosis of the conjunctiva, ${ }^{96}$ conjunctival manifestations of actinic prurigo, ${ }^{97}$ keratitis of Senter syndrome (keratitis-ichthyosis deafness), ${ }^{98}$ delayed onset bilateral diffuse lamellar keratitis after laser in situ keratomileusis, ${ }^{99}$ and microcrystalline keratopathy caused by streptococcus. ${ }^{100}$ However, the evidence seems inadequate to justify the use of topical CsA in these conditions.

\section{CONCLUSIONS}

Topical CsA has been used in ophthalmology since the early 1980s. Based on the available evidence, CsA eye drops seem to be safe. No serious side effects were reported with the $0.05 \%, 0.5 \%$, or $2 \%$ preparations, used for periods of up to
12 months. Current literature supports the efficacy of topical CsA in the treatment of various ocular surface disorders, particularly the dry eye syndrome and severe allergic keratoconjunctivitis. Future studies should be directed to comparing the efficacy of topical CsA with that of corticosteroids and to its ability to change the natural course of some of these disorders during longer term follow up.

\section{Authors' affiliations}

S Tatlipinar, E K Akpek, The Wilmer Eye Institute, Johns Hopkins School of Medicine, Baltimore, MD, USA

S Tatlipinar, Department of Ophthalmology, Pamukkale University School of Medicine, Denizli, Turkey

Competing interests: none declared

Dr Akpek received unrestricted research grant from Allergan Inc, Irvine, CA (see reference 58). She is supported in part by a William and Mary Greve Scholarship from Research to Prevent Blindness.

\section{REFERENCES}

1 Baudouin C. The pathology of dry eye. Surv Ophthalmol 2001;45:211-20.

2 Johnson ME, Murphy PJ. Changes in the tear film and ocular surface from dry eye syndrome. Prog Retin Eye Res 2004;23:449-74.

3 Nussenblatt RB, Palestine AG. Cyclosporin: immunology, pharmacology and therapeutic uses. Surv Ophthalmol 1986;31:159-69.

4 Belin MW, Bouchard CS, Phillips TM. Update on topical cyclosporin A: background, immunology, and pharmacology. Cornea 1990;9:184-95.

5 Williams DL. A comparative approach to topical cyclosporin therapy. Eye 1997;11:453-64

6 Borel JF, Feurer C, Gubler HU, et al. Biological effects of cyclosporin A: a new antilymphocytic agent. Agents Actions 1976:6:468-75.

7 Calne RY, White DJ, Thiru S, et al. Cyclosporin A in patients receiving renal allografts from cadaver donors. Lancet 1978;2:1323-7.

8 Coster DJ, Shepherd WF, Fook TC, et al. Prolonged survival of corneal allografts in rabbits treated with cyclosporin A. Lancet, 1979;2, 688-9.

9 Hunter PA, Wilhelmus KR, Rice NS, et al. Cyclosporin A applied topically to the recipient eye inhibits corneal graft rejection. Clin Exp Immunol 1981;45:173-7.

10 Hoffmann $F$, Wiederholt $M$. [Local treatment of corneal transplants in the human with cyclosporin A.] Klin Monatsbl Augenheilkd, 1985;187:92-6.

11 Holland EJ, Olsen TW, Ketcham JM, et al. Topical cyclosporin A in the treatment of anterior segment inflammatory disease. Cornea 1993;12:413-9.

12 Gunduz K, Ozden O. Therapeutic use of topical cyclosporine. Ann Ophthalmol 1993;25:182-6.

13 Lemp MA. Report of the National Eye Institute/Industry Workshop on Clinical Trials in Dry Eyes. CLAO J 1995;21:221-32.

14 Doughty MJ, Fonn D, Richter D, et al. A patient questionnaire approach to estimating the prevalence of dry eye symptoms in patients presenting to optometric practices across Canada. Optom Vis Sci 1997;74:624-31.

15 Stern ME, Gao J, Siemasko KF, et al. The role of the lacrimal functional unit in the pathophysiology of dry eye. Exp Eye Res 2004;78:409-16.

16 Stern ME, Gao J, Schwalb TA, et al. Conjunctival T-cell subpopulations in Sjogren's and non-Sjogren's patients with dry eye. Invest Ophthalmol Vis Sci 2002;43:2609-14

17 Sullivan DA, Wickham LA, Rocha EM, et al. Androgens and dry eye in Sjogren's syndrome. Ann N Y Acad Sci 1999;876:312-24.

18 Marsh P, Pflugfelder SC. Topical nonpreserved methylprednisolone therapy for keratoconjunctivitis sicca in Sjogren syndrome. Ophthalmology 1999;106:811-6.

19 Sainz De La Maza Serra M, Simon Castellvi C, Kabbani O. Nonpreserved topical steroids and lacrimal punctal occlusion for severe keratoconjunctivitis sicca. Arch Soc Esp Oftalmol 2000;75:751-6.

20 Laibovitz RA, Solch S, Andriano K, et al. Pilot trial of cyclosporin 1\% ophthalmic ointment in the treatment of keratoconjunctivitis sicca. Cornea $1993 ; 12: 315-23$

21 Power WJ, Mullaney P, Farrell M, et al. Effect of topical cyclosporin A on conjunctival T cells in patients with secondary Sjogren's syndrome. Cornea 1993;12:507-11.

22 Gunduz K, Ozdemir O. Topical cyclosporin treatment of keratoconjunctivitis sicca in secondary Sjogren's syndrome. Acta Ophthalmol (Copenh) 1994;72:438-42.

23 Stevenson D, Tauber J, Reis BL. Efficacy and safety of cyclosporin A ophthalmic emulsion in the treatment of moderate-to-severe dry eye disease: a dose-ranging, randomized trial. The Cyclosporin A Phase 2 Study Group. Ophthalmology 2000;107:967-74.

24 Sall K, Stevenson OD, Mundorf TK, et al. Two multicenter, randomized studies of the efficacy and safety of cyclosporin ophthalmic emulsion in moderate to severe dry eye disease. CsA Phase 3 Study Group. Ophthalmology 2000;107:631-9.

25 Kunert KS, Tisdale AS, Gipson IK. Goblet cell numbers and epithelial proliferation in the conjunctiva of patients with dry eye syndrome treated with cyclosporin. Arch Ophthalmol 2002;120:330-7. 
26 Kunert KS, Tisdale AS, Stern ME, et al. Analysis of topical cyclosporin treatment of patients with dry eye syndrome: effect on conjunctiva lymphocytes. Arch Ophthalmol 2000;1 18:1489-96.

27 Turner K, Pflugfelder SC, Ji Z, et al. Interleukin-6 levels in the conjunctival epithelium of patients with dry eye disease treated with cyclosporin ophthalmic emulsion. Cornea 2000;19:492-6.

28 Ukponmwan CU. Vernal keratoconjunctivitis in Nigerians: 109 consecutive cases. Trop Doct 2003;33:242-5.

29 El Hennawi M. A double blind placebo controlled group comparative study of ophthalmic sodium cromoglycate and nedocromil sodium in the treatment of vernal keratoconjunctivitis. Br J Ophthalmol 1994;78:365-9.

30 Bonini S, Barney NP, Schiavone M, et al. Effectiveness of nedocromil sodium $2 \%$ eyedrops on clinical symptoms and tear fluid cytology of patients with vernal conjunctivitis. Eye 1992;6:648-52.

31 Foster CS. Evaluation of cromolyn sodium in the treatment of vernal keratoconjunctivitis. Ophthalmology 1988;95:194-201.

32 Resnikoff S, Cornand G, Filliard G, et al. Limbal vernal keratoconjunctivitis in the tropics. Rev Int Trach Pathol Ocul Trop Subtrop Sante Publique 1988;65:21-72.

33 Baryishak YR, Zavaro A, Monselise M, et al. Vernal keratoconjunctivitis in an Israeli group of patients and its treatment with sodium cromoglycate. Br J Ophthalmol 1982;66:118-22.

34 Abiose A. Paediatric ophthalmic problems in Nigeria. J Trop Pediatr 1985;31:30-5

35 Tabbara KF. Ocular complications of vernal keratoconjunctivitis. Can J Ophthalmol 1999:34:88-92.

36 Tabbara KF, Ross-Degnan D. Blindness in Saudi Arabia. JAMA $1986 ; 255: 3378-84$

37 Herse P, Gothwal VK. Survey of visual impairment in an Indian tertiary eye hospital. Indian J Ophthalmol 1997;45:189-93.

38 Akpek EK, Hasiripi H, Christen WG, et al. A randomized trial of low-dose, topical mitomycin-C in the treatment of severe vernal keratoconjunctivitis. Ophthalmology 2000;107:263-9.

39 Abu el-Asrar AM, Van den Oord JJ, Geboes K, et al. Immunopathological study of vernal keratoconjunctivitis. Graefes Arch Clin Exp Ophthalmol 1989;227:374-9.

40 El-Asrar AM, Tabbara KF, Geboes K, et al. An immunohistochemical study of topical cyclosporin in vernal keratoconjunctivitis. Am J Ophthalmol 1996;121:156-61.

41 BenEzra D, Pe'er J, Brodsky M, et al. Cyclosporin eyedrops for the treatment of severe vernal keratoconjunctivitis. Am J Ophthalmol 1986;101:278-82

42 Secchi AG, Tognon MS, Leonardi A. Topical use of cyclosporin in the treatment of vernal keratoconjunctivitis. Am J Ophthalmol 1990;1 10:641-5.

43 Bleik JH, Tabbara KF. Topical cyclosporin in vernal keratoconjunctivitis. Ophthalmology $1991 ; 98: 1679-84$.

44 Avunduk AM, Avunduk MC, Erdol $\mathrm{H}$, et al. Cyclosporin effects on clinical findings and impression cytology specimens in severe vernal keratoconjunctivitis. Ophthalmologica 2001;215:290-3

45 Pucci N, Novembre E, Cianferoni A, et al. Efficacy and safety of cyclosporin eyedrops in vernal keratoconjunctivitis. Ann Allergy Asthma Immunol 2002;89:298-303.

46 Cetinkaya A, Akova YA, Dursun D, et al. Topical cyclosporin in the management of shield ulcers. Cornea 2004;23:194-200.

47 Hanifin JM. Epidemiology of atopic dermatitis. Monogr Allergy 1987;21:116-31.

48 Garrity JA, Liesegang TJ. Ocular complications of atopic dermatitis. Can J Ophthalmol 1984;19:19-24.

49 Power WJ, Tugal-Tutkun I, Foster CS. Long-term follow-up of patients with atopic keratoconjunctivitis. Ophthalmology 1998;105:637-42.

50 Belfort R, Marbeck P, Hsu CC, et al. Epidemiological study of 134 subjects with allergic conjunctivitis. Acta Ophthalmol Scand Suppl 2000;230:38-40.

51 Tuft SJ, Kemeny DM, Dart JK, et al. Clinical features of atopic keratoconjunctivitis. Ophthalmology 1991;98:150-8.

52 Foster CS, Rice BA, Dutt JE. Immunopathology of atopic keratoconjunctivitis. Ophthalmology 1991;98:1190-6.

53 Metz DP, Hingorani M, Calder VL, et al. T-cell cytokines in chronic allergic eye disease. J Allergy Clin Immunol 1997;100:817-24.

54 Calder VL, Jolly $G$, Hingorani $M$, et al. Cytokine production and mRNA expression by conjunctival T-cell lines in chronic allergic eye disease. Clin Exp Allergy 1999;29:1214-22.

55 Foster CS, Calonge M. Atopic keratoconjunctivitis. Ophthalmology 1990:97:992-1000.

56 Hoang-Xuan T, Prisant $O$, Hannouche D, et al. Systemic cyclosporine A in severe atopic keratoconjunctivitis. Ophthalmology 1997; 104:1300-5.

57 Hingorani M, Moodaley L, Calder VL, et al. A randomized, placebo controlled trial of topical cyclosporin A in steroid-dependent atopic keratoconjunctivitis. Ophthalmology 1998;105:1715-20.

58 Akpek EK, Dart JK, Watson S, et al. A randomized trial of topical cyclosporin $0.05 \%$ in topical steroid-resistant atopic keratoconjunctivitis. Ophthalmology 2004;111:476-82.

59 Tomida I, Schlote T, Brauning J, et al. [Cyclosporin A 2\% eyedrops in therapy of atopic and vernal keratoconjunctivitis.] Ophthalmologe 2002;99:761-7.

60 Hingorani M, Calder VL, Buckley RJ, et al. The immunomodulatory effect of topical cyclosporin A in atopic keratoconjunctivitis. Invest Ophthalmol Vis Sci 1999:40:392-9.

61 Foster CS, Forstot SL, Wilson LA. Mortality rate in rheumatoid arthritis patients developing necrotizing scleritis or peripheral ulcerative keratitis: effects of systemic immunosuppression. Ophthalmology 1984;91:1253-63.

62 Pfister RR, Murphy GE. Corneal ulceration and perforation associated with Sjogren's syndrome. Arch Ophthalmol 1980;98:89-94.
63 Zierhut M, Thiel HJ, Weidle EG, et al. Topical treatment of severe corneal ulcers with cyclosporin A. Graefes Arch Clin Exp Ophthalmol 1989;227:30-5.

64 Kervick GN, Pflugfelder SC, Haimovici R, et al. Paracentral rheumatoid corneal ulceration: clinical features and cyclosporin therapy. Ophthalmology 1992;99:80-8.

65 Gottsch JD, Akpek EK. Topical cyclosporin stimulates neovascularization in resolving sterile rheumatoid central corneal ulcers. Trans Am Ophthalmol Soc 2000:98:81-7

66 Liegner JT, Yee RW, Wild JH. Topical cyclosporin therapy for ulcerative keratitis associated with rheumatoid arthritis. Am J Ophthalmol 1990; 109:610-2

67 Thygeson P. Superficial punctate keratitis. JAMA 1950;144:1544-9.

68 Nagra PK, Rapuano CJ, Cohen EJ, et al. Thygeson's superficial punctate keratitis: ten years' experience. Ophthalmology 2004;111:34-7.

69 Hardten DR, Doughman DJ, Holland EJ, et al. Persistent superficial punctate keratitis after resolution of chlamydial follicular conjunctivitis. Cornea 1992;11:360-3.

70 Reinhard T, Roggendorf M, Fengler I, et al. PCR for varicella zoster virus genome negative in corneal epithelial cells of patients with Thygeson's superficial punctate keratitis. Eye 2004;18:304-5.

71 Goldberg DB, Schanzlin DJ, Brown SI. Management of Thygeson's superficial punctate keratitis. Am J Ophthalmol 1980;89:22-4.

72 Forstot SL, Binder PS. Treatment of Thygeson's superficial punctate keratopathy with soft contact lenses. Am J Ophthalmol 1979;88:186-9

73 Reinhard T, Sundmacher R. [Local cyclosporin A therapy in Thygeson superficial punctate keratitis--a pilot study.] Klin Monatsbl Augenheilkd, 1996;209:224-7.

74 Reinhard T, Sundmacher R. Topical cyclosporin A in Thygeson's superficial punctate keratitis. Graefes Arch Clin Exp Ophthalmol 1999;237:109-12.

75 Del Castillo JM, Del Castillo JB, Garcia-Sanchez J. Effect of topical cyclosporin A on Thygeson's superficial punctate keratitis. Doc Ophthalmol 199697:93:193-8.

76 Schuster V, Seregard S. Ligneous conjunctivitis. Surv Ophthalmol 2003:48:369-88.

77 Hidayat AA, Riddle PJ. Ligneous conjunctivitis: a clinicopathologic study of 17 cases. Ophthalmology 1987;94:949-59.

78 Watts P, Suresh P, Mezer E, et al. Effective treatment of ligneous conjunctivitis with topical plasminogen. Am J Ophthalmol 2002;133:451-5.

79 Holland EJ, Chan CC, Kuwabara T, et al. Immunohistologic findings and results of treatment with cyclosporin in ligneous conjunctivitis. Am J Ophthalmol 1989; 107:160-6

80 Rao SK, Biswas J, Rajagopal R, et al. Ligneous conjunctivitis: a clinicopathologic study of 3 cases. Int Ophthalmol 1998-99;22:201-6.

81 Rubin BI, Holland EJ, de Smet MD, et al. Response of reactivated ligneous conjunctivitis to topical cyclosporin. Am J Ophthalmol 1991;112:95-6.

82 Boyd AS, Neldner KH. Lichen planus. J Am Acad Dermatol 1991;25:593-619.

83 Thorne JE, Jabs DA, Nikolskaia OV, et al. Lichen planus and cicatrizing conjunctivitis: characterization of five cases. Am J Ophthalmol 2003; 136:239-43.

84 Neumann R, Dutt CJ, Foster CS. Immunohistopathologic features and therapy of conjunctival lichen planus. Am J Ophthalmol 1993;115:494-500.

85 Oliver GF, Winkelmann RK. Treatment of lichen planus. Drugs 1993;45:56-65.

86 Levell NJ, Munro CS, Marks JM. Severe lichen planus clears with very lowdose cyclosporin. Br J Dermatol 1992;127:66-7.

87 Crompton DO. Immuno-suppressive drug treatment of keratitis sicca, including an example of lichen planus of the conjunctiva. Aust N Z J Surg 1968;38:143-6.

88 Leonardi A, DeFranchis G, Fregona IA, et al. Effects of cyclosporin A on human conjunctival fibroblasts. Arch Ophthalmol 2001;119:1512-7.

89 Rhee MK, Mootha VV. Bilateral keratoconjunctivitis associated with lichen planus. Cornea 2004;23:100-5.

90 Pakravan M, Klesert T, Akpek EK. Isolated conjunctival lichen planus. Cornea (in press).

91 Theodore FH. Further observations on superior limbic keratoconjunctivitis. Trans Am Acad Ophthalmol Otolaryngol 1967;71:341-51.

92 Cher I. Superior limbic keratoconjunctivitis: multifactorial mechanical pathogenesis. Clin Experiment Ophthalmol 2000;28:181-4

93 Perry HD, Doshi-Carnevale S, Donnenfeld ED, et al. Topical cyclosporin A $0.5 \%$ as a possible new treatment for superior limbic keratoconjunctivitis. Ophthalmology 2003;110:1578-81.

94 Zhao JC, Jin XY. Immunological analysis and treatment of Mooren's ulcer with cyclosporin A applied topically. Cornea 1993;12:481-8.

95 Shimura M, Yasuda K, Fuse N, et al. Effective treatment with topical cyclosporin A of a patient with Cogan syndrome. Ophthalmologica 2000;214:429-32

96 Akpek EK, Ithan-Sarac O, Green WR. Topical cyclosporin in the treatment of chronic sarcoidosis of the conjunctiva. Arch Ophthalmol 2003;121:1333-5.

97 McCoombes JA, Hirst LW, Green WR. Use of topical cyclosporin for conjunctival manifestations of actinic prurigo. Am J Ophthalmol 2000;130:830-1.

98 Derse M, Wannke E, Payer H, et al. [Successful topical cyclosporin A in the therapy of progressive vascularising keratitis in keratitis-ichthyosis-deafness (KID) syndrome (Senter syndrome).] Klin Monatsbl Augenheilkd 2002;219:383-6.

99 Chung MS, Pepose JS, El-Agha MS, et al. Confocal microscopic findings in a case of delayed-onset bilateral diffuse lamellar keratitis after laser in situ keratomileusis. J Cataract Refract Surg 2002;28:1467-70.

100 Touzeau O, Borderie V, Razavi S, et al. [Use of topical cyclosporin in microcrystalline keratopathy due to streptococcus.] J Fr Ophtalmol 1999;22:662-5. 